\title{
AAV-mediated gene therapy for metabolic diseases: dosage and reapplication studies in the molybdenum cofactor deficiency model Rita Hahnewald*, Waja Wegner and Jochen Reiss
}

\author{
Address: Institut für Humangenetik der Universität Göttingen, Heinrich-Düker-Weg 12, 37073 Göttingen, Germany \\ Email: Rita Hahnewald* - r.hahnewald@gmx.de; Waja Wegner - w.wegner@gmx.de; Jochen Reiss - jreiss@gwdg.de \\ * Corresponding author
}

Published: 18 June 2009

Genetic Vaccines and Therapy 2009, 7:9 doi:10.1186/1479-0556-7-9

This article is available from: http://www.gvt-journal.com/content/7/1/9

(C) 2009 Hahnewald et al; licensee BioMed Central Ltd.

This is an Open Access article distributed under the terms of the Creative Commons Attribution License (http://creativecommons.org/licenses/by/2.0), which permits unrestricted use, distribution, and reproduction in any medium, provided the original work is properly cited.
Received: 20 March 2009

Accepted: 18 June 2009

\begin{abstract}
In a mouse model for molybdenum cofactor deficiency as an example for an inherited metabolic disease we have determined the dosage of recombinant AAV necessary to rescue the lethal deficiency phenotype. We demonstrated long-term expression of different expression cassettes delivered in a chimeric AAV capsid of serotype I/2 and compared different routes of application. We then studied the effect of double and triple injections at different time points after birth and found a short neonatal window for non-response of the immune system. Exposition with rAAV capsids within this window allows transgene expression after a second rAAV transduction later. However, exposition within this window does not trigger immunotolerance to the viral capsid, which limits rAAV-mediated refurbishment of the transgene to only one more application outside this permissive window.
\end{abstract}

\section{Findings}

In mammals, molybdenum cofactor (MoCo) is essential for the activity of sulfite oxidase, xanthine dehydrogenase and aldehyde oxidase [1]. The gene products of the human genes MOCS1, MOCS2, MOCS3 and GEPH are required for the biosynthesis of MoCo [2]. A mutational block of these genes leads to MoCo deficiency (OMIM \#252150) associated with a progressive neuronal damage and death before adolescence in affected patients. The majority of patients suffer from type A deficiency and harbour mutations in the gene MOCS1 [3].Mocs1 knockoutmice show no detectable residual Mocs 1 mRNA levels and display a severe phenotype reflecting the biochemical characteristics of human MoCo-deficient patients [4].

Recently, we described the phenotypical rescue of Mocs1deficient mice by intrahepatic injection of a recombinant adeno-associated virus (rAAV) vector carrying an expres- sion cassette for the human MOCS1 cDNA [5]. The MOCS 1 expression cassette has been describe before and essentially contains a hybrid promoter consisting of a cytomegalovirus (CMV) enhancer, a human $\beta$-actin promoter, exons 1 through 10 of the human MOCS 1 gene, a deleted intron 9, which allows for alternative splicing leading to the gene products MOCS1A and MOCS1B and a bovine growth hormone (BGH) polyadenylation (poly A)-signal. MOCS1A and MOCS1B together produce the relatively stable intermediate $\mathrm{CPMP}$, which is further processed to active MoCo by the products of the genes MOCS2, MOCS3 and GEPH.

Transfer of the MOCS1 gene was primarily aimed at transduction of hepatocytes, since the liver is the primary organ involved in detoxification of sulfite to sulphate by sulfite oxidase [6]. In the meantime, mice rescued by the intrahepatic rAAV-MOCS1 reached a lifespan of up to 666 days. 
To study the long-term expression profile after AAV transduction, we here analyzed wild-type mice, which had received an intrahepatic injection of AAV encoding the green fluorescent protein (AAV-EGFP) on day 6 after birth. The EGFP expression cassette contains the coding sequence for EGFP instead of the MOCS1 CDNA.

Recombinant viruses were generated by using a mixture of AAV helper plasmids encoding serotype 1 and 2 in ratio of $1: 1$. Previous studies had demonstrated that the chimeric AAV1/2 vector triggers a higher expression level both in liver and in muscle as compared to serotypes 1 or 2 [7]. Figure 1 shows that the intrahepatic application using AAV1/2 capsids leads to predominant expression in heart and liver, where the transgene product is detectable for more than 10 months. However, the rate of transgene expressing cells drops down from almost $100 \%$ in liver [5] to approximately 5\%, while in the heart after 10 months still approximately $50 \%$ of cells expressed EGFP (figure 1). A similar expression profile has been observed in mice carrying the EGFP expression cassette in all cells after microinjection of fertilized oozytes and subsequent breeding (data not shown), which indicates that not the rate of transduction but rather persistence of expression accounts for this organ-specific difference.

As a further approach to the treatment of patients, we investigated the efficacy of systemic AAV delivery. Comparative studies 1 month after rAAV-EGFP application showed similar tissue transduction after either intrahepatic or intravenous injection [5]. Using the MOCS1 expression cassette in an AAV 1/2 capsid, we here studied the effect of systemic delivery by tail vein injections. For this application we used mice with a minimum body weight of around $15 \mathrm{~g}$ corresponding to an age of approximately 40 days. Untreated Mocs 1 deficient mice are unable to build CPMP, the first intermediate in the MoCo biosynthesis, and die on average 7.5 days after birth [4]. We pretreated Mocs 1 -deficient mice until day 40 with periodic intrahepatic injections of purified CPMP from Escherichia coli [8] to achieve a suitable size for tail vein injection.

Intrahepatic injections were done every other day with increasing amounts from $2 \mu \mathrm{g}$ in the first week up to $32 \mu \mathrm{g}$ from the 5 th week onward. On day 40 , they received $4 \times$ $10^{9}$ tu AAV-MOCS1 by a single intravenous injection ( $\mathrm{n}=$ $5)$. Control animals $(n=10)$ received the rAAV vector, in which the MOCS1 cDNA was replaced by the fluorescent reporter EGFP cDNA. These controls died on average 11 days after the final cPMP injection. In contrast, none of the mice treated with AAV-MOCS1 died from MoCo deficiency. Two of them have reached a life span of approximately 500 days without cPMP supplementation (figure
2 , blue line). The other three mice were sacrificed in the course of reapplication studies (see below).

Considering the lower dosage of $4 \times 10^{9}$ tu AAV-MOCS1 for systemic delivery, as compared to $1 \times 10^{10}$ tu for the intrahepatic injections described previously [5] and above, the results described here indicate a similar efficacy for both application schemes. All five above described mice had been mated and were fertile. The offspring ( $\mathrm{n}=$ 64) died on average on day 5.35 after birth, which corresponds to the lifespan of untreated homozygous Mocs 1 knockout mice from matings of heterozygous mice. This is indirect evidence that the intravenous tail vein injections did not result in germ line transmission of the vector genome.

To estimate the necessary dosage for the treatment of humans, we determined the minimal dosage required to rescue the deficiency phenotype via the intravenous route. 20 neonatal Mocs1-deficient mice were pretreated with purified CPMP as described above. At day 40 after birth, the animals obtained a single intravenous tail vein injection containing various amounts of AAV-MOCS1 in phosphate-buffered saline. First, we investigated the effect of a thirty-fold reduced dosage of AAV-MOCS1 as compared to the experiments described above, i.e. $1.5 \times 10^{8} \mathrm{tu}(\mathrm{n}=8)$. Mice of this group died on average $28.75 \pm 6.5$ days after the AAV-MOCS1 injection and discontinuation of CPMP substitution (figure 2, red line). This reduced dosage apparently is not sufficient to rescue the lethal phenotype.

Next, we studied the effect of an intermediate dosage of 4 $\times 10^{8}$ tu AAV-MOCS 1 on day 40 after CPMP pre-treatment $(\mathrm{n}=12)$. The mice of this group died on average $238.5 \pm$ 124.4 days after AAV-MOCS1 injection and CPMP withdrawal at day 40 after birth (figure 2, green line). All animals of this group were mated and all but one were fertile. Again, the offspring died within the range of untreated animals (data not shown). The observed high variance of the life span suggests that the intermediate dosage of $4 \times$ $10^{8}$ tu AAV-MOCS1 represents a borderline result and indicates a range for the minimal dosage required for abolishing the MoCo deficiency phenotype. With a maximum body weight of $40 \mathrm{~g}$ for the mice used here this would correspond to $1 \times 10^{10}$ tu per kg body weight. A one year old child with a body weight of $10 \mathrm{~kg}$ thus would require $1 \times 10^{11}$ tu of $A A V-M O C S 1$, which is within the range of GMP production facilities.

Although one single injection could abolished the phenotype of the MoCo-deficiency, our murine model allows a prediction only for the natural life span of mice, i.e. 2 to 3 years. In contrast to long-lasting expression in mice, rats, hemophilic dogs and nonhuman primates, expression at therapeutic levels in humans was limited to a period of 


\section{5 months}

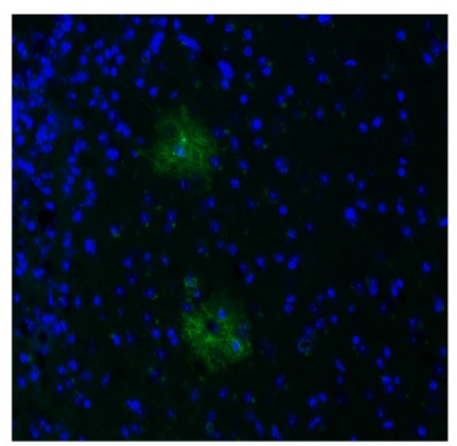

Brain

Heart

\section{Kidney}
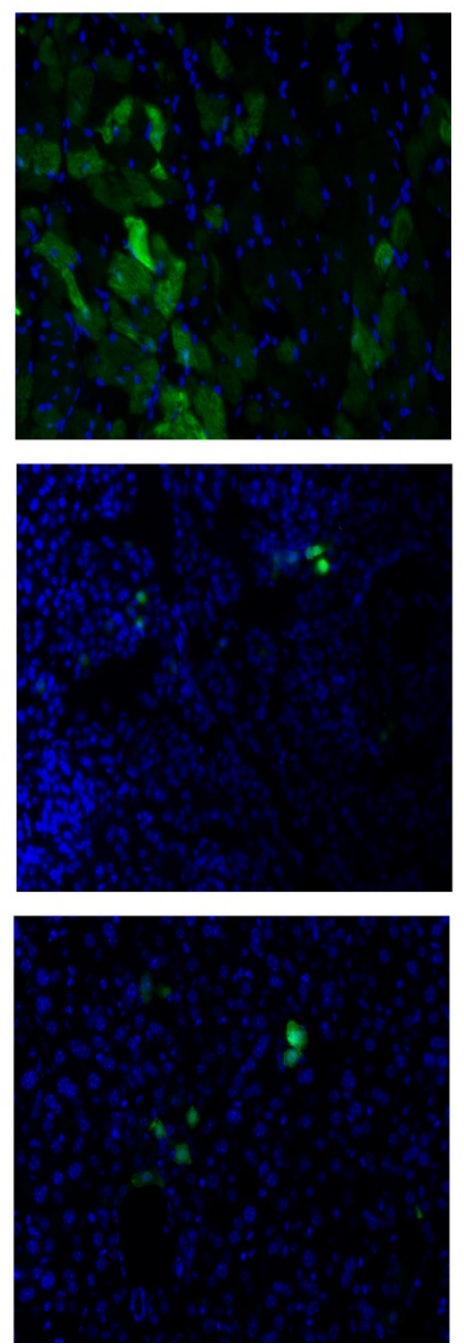


negative control


Figure I

Long-term expression after AAVI/2 transduction. Wild-type mice obtained a single intrahepatic AAV-EGFP injection containing $4.5 \times 10^{9}$ tu on day 6 . After 10.5 months the mice were perfused with $4 \%$ paraformaldehyde. Tissue for expression analysis was cryoprotected in sucrose and stored frozen at $-80^{\circ}$ until analysis. Cryostat sections of $3 \mu \mathrm{m}$ thickness were prepared for EGFP expression analysis. Pictures were recorded by Fluorescent microscope BX60 from Olympus. Fluorescence is shown as an overlay of EGFP (green) and nuclear DAPI (blue) fluorescence. The images were recorded with an exposure time of $50 \mathrm{~ms}$ for DAPI and $500 \mathrm{~ms}$ for EGFP (I s for negative expression). 


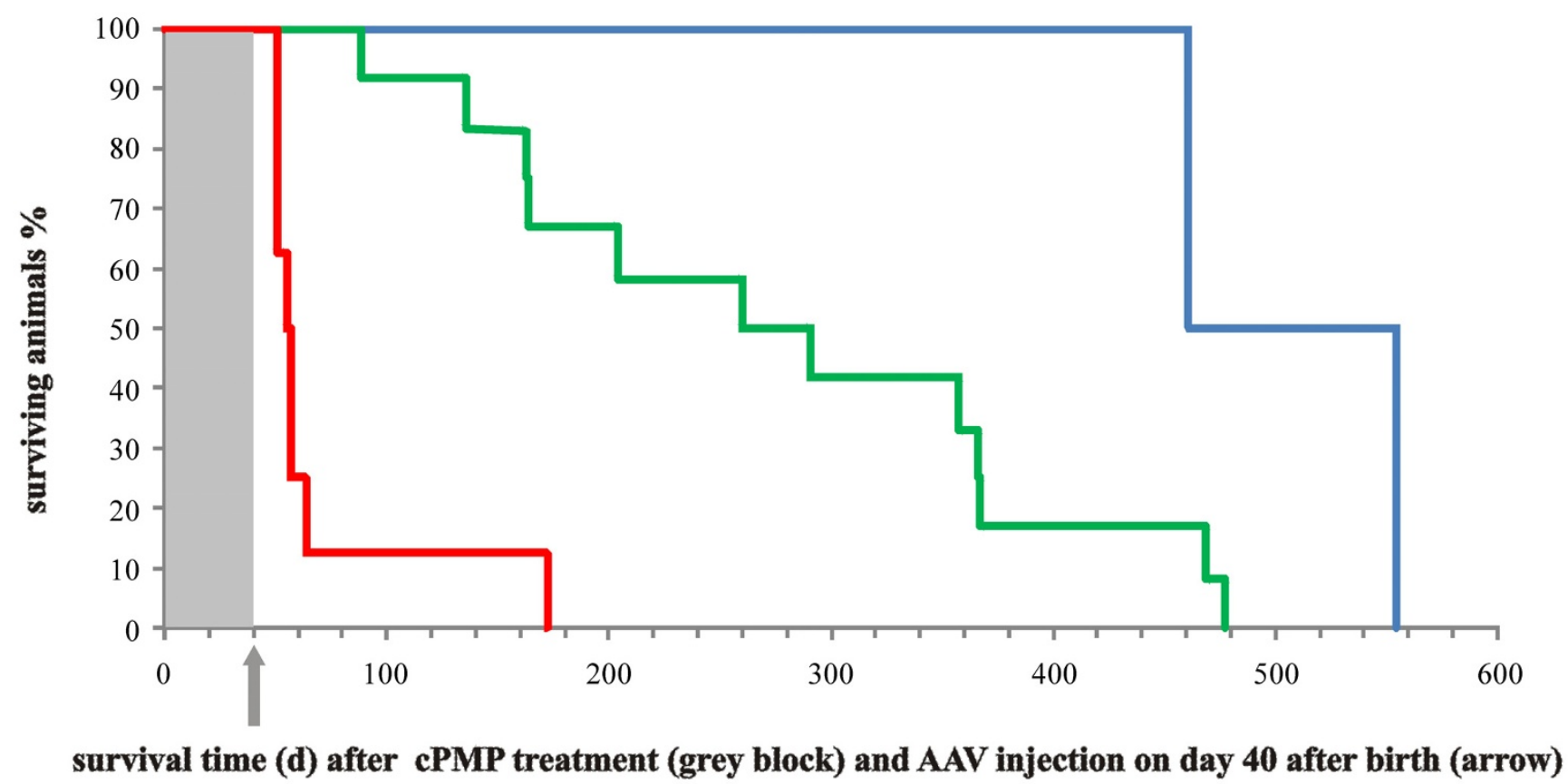

$4 \times 10^{9}$ tu $\quad 4 \times 10^{8}$ tu $1.5 \times 10^{8}$ tu

Figure 2

De-escalations studies of AAVI/2-MOCS I delivery. Survival of Mocs I-deficient mice injected i.v. on day 40 after birth with various amounts of AAV-MOCSI. Group A (blue) was injected with $4 \times 10^{9}$ tu $(\mathrm{n}=2)$. Group B (red) received I.5 $\times 10^{8}$ tu AAV-MOCSI $(n=8)$. Group $C$ (green) received a single injection containing $4 \times 10^{8}$ tu $(n=12)$.

around 8 weeks [9-14]. This difference was mainly attributed to prior infection of the human patients with natural AAVs in combination with helper adenovirus [15]. This leads to formation of memory CD8 ${ }^{+} \mathrm{T}$ cells and their activation upon reexposure to the AAV capsid.

Thus, the possibility of repeated vector administrations in the treatment of patients from an immunological point of view is an important issue to be addressed. To this end, we investigated the feasibility of successful rAAV re-administration at different time points in the MoCo deficient mouse model and compared the reapplication possibilities in different developmental stages. AAV serotype 1/2 (in a 50:50 ratio) was used throughout.

In the first experiment, two Mocs 1-deficient mice were pretreated for 40 days after birth with purified CPMP as described above. At day 40, the two animals obtained a single intravenous tail vein injection of $65 \mu$ l containing 4 $\times 10^{9}$ tu AAV-MOCS1. The successful transduction of this first injection was confirmed by the prolonged lifespan of the otherwise MoCo-deficient animals. The mice were injected for the second time after three months with an AAV vector carrying a reporter gene vector $\left(4 \times 10^{9} \mathrm{tu}\right.$ AAV1/2-EGFP). As a positive control for the second injection, two wild-type mice obtained only $4 \times 10^{9}$ tu AAV1/ 2-EGFP. The negative controls were two wild-mice without any treatment. Two months after AAV1/2-EGFP injections, all six mice were perfused with paraformaldehyde. The second AAV injection did not result in any observable expression of EGFP in the liver (figure 3).

Studies on hemophilia B mice showed that in utero or neonatally AAV-treated mice do not develop antibodies to the AAV capsid after the first injection [16]. They demonstrated that it is possible to establish tolerance to the transgene product human factor IX by these early injections and to obtain long-term therapeutic levels in immunocompetent mice. Here, the transgene products of the MOCS 1 expression cassette are localized intracellular and thus not accessible for antibodies. We therefore concentrated on the existence of a "window of opportunity" to induce tolerance against the viral capsid in repeated exposures. 


\section{A) Repeated injection of serotype AAV1/2}



B) Positive control

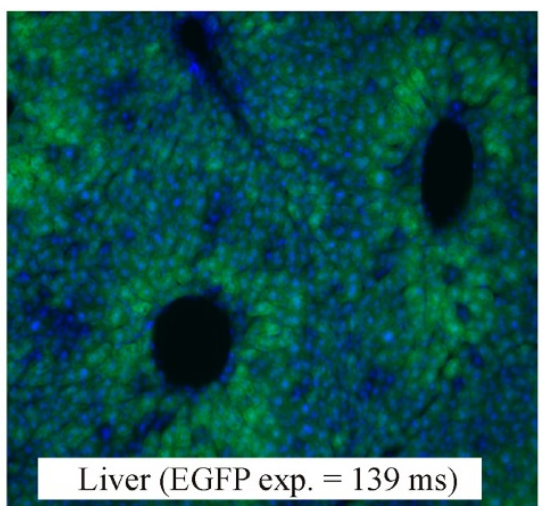

C) Negative control

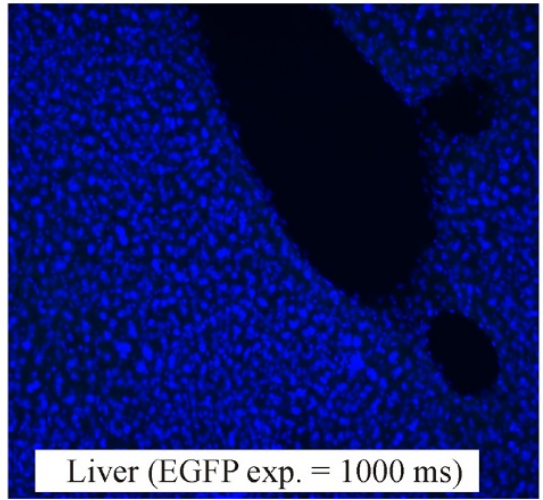

Figure 3

Vector reapplication in adolescence. Liver sections of adult mice after different treatment schemes. Exposure times (exp.) for EGFP are indicated (for further details see figure I). A) First injection i.v. on day 40 with AAV-MOCSI, second injection intrahepatic with AAV-EGFP after 3 months. B) Only one intrahepatic AAV-EGFP injection 4 months after birth. C) No injection.

Three groups of two Mocs 1 -deficient mice each received an intrahepatic injection of $50 \mu \mathrm{l}$ containing $1 \times 10^{9} \mathrm{tu} \mathrm{AAV}-$ MOCS 1 on day 1 , day 10 or day 20 , respectively. The mice were injected for the second time three months after the first injection with $50 \mu \mathrm{l}$ containing $1 \times 10^{9}$ tu AAV-EGFP. Two wild-type mice served as negative controls and obtained no second injection. Additionally, for each time point two wild-type mice served as positive control for the AAV-EGFP injections and obtained only the second injection with $1 \times 10^{9}$ tu AAV-EGFP. Two months after the AAV-EGFP injections, all mice were perfused with $4 \%$ paraformaldehyde. The groups with the first injection at day 10 or day 20 the second injection of AAV-EGFP did not result in any observable expression of EGFP in the liver (figure $4 a, b)$. In the group injected first at day 1 after birth, both mice showed strong EGFP-expression (figure 4c), which confirms that the immune system shortly after birth does not react to the vector capsid.

Since the products of the MOCS 1 and the EGFP expression cassette do not share cross-reacting epitopes, we could investigate the potential of early injections to induce an immune tolerance against the viral capsid by triple injections. Two wild-type mice obtained a first intrahepatic injection of $1 \times 10^{9}$ tu AAV-MOCS 1 on day 1 after birth and a second injection with $1 \times 10^{9}$ tu AAVMOCS 1 on day 10 . After two months they received a third injection of $1 \times 10^{9}$ tu AAV-EGFP. A positive control for the AAV-EGFP injections obtained only a single injection of $1 \times 10^{9}$ tu AAV-EGFP. Two months after AAV-EGFP injections, all mice were perfused with $4 \%$ paraformaldehyde. Here, the rAAV-EGFP injections did not lead to an EGFP expression (figure 4d), even though the first expo- sure to AAV1/2 capsid occurred on day 1 after birth (compare figure $4 \mathrm{c}$ ). While the role of a cytotoxic T-cell response in mice remains unclear, the immune system clearly built neutralizing antibodies (nABs) $[17,18]$ against the viral vector after the second injection of viral vector. Thus, the early exposure of the immune system to viral vector capsid allows a successful second application but does not induce an immunotolerance against the capsid proteins.

An important factor in $\mathrm{nAB}$ response is the time point of viral vector administration. The group of Petry et al [19]. showed that the efficacy of readministration is dependent on the titer of $\mathrm{nAB}$ and that the level of $\mathrm{nABs}$ is proportional to the virus dose used for the first injection. Since repeated AAV treatment in adolescence leads to immune responses, future experiments will have to show whether the combination of early first exposure, a lower dosage of virus and/or temporary immunosuppression (e.g. with cyclosporine) facilitates more successful rAAV reapplications.

\section{Competing interests}

The authors declare that they have no competing interests.

\section{Authors' contributions}

$\mathrm{RH}$ participated in the design of the study, carried out the practical work and drafted the manuscript. WW participated in the practical work and discussions. JR designed this study and edited the manuscript. All authors read and approved the final manuscript. 
A)

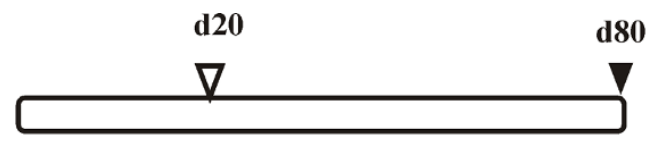

d80
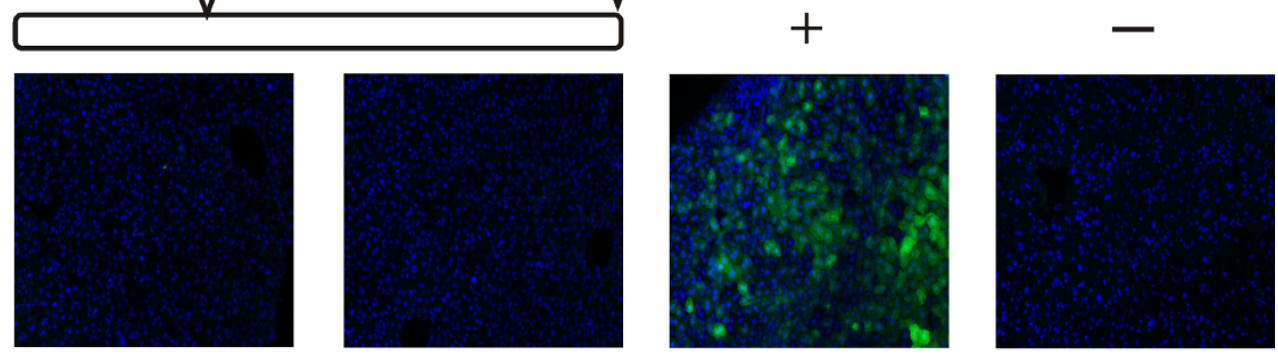

B)


C)
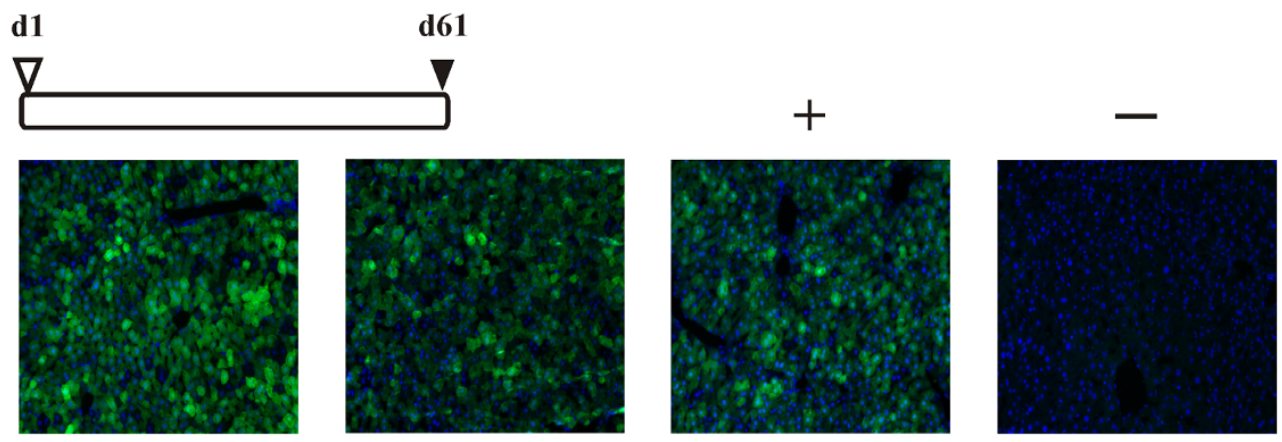

d1 d10

d71

D)
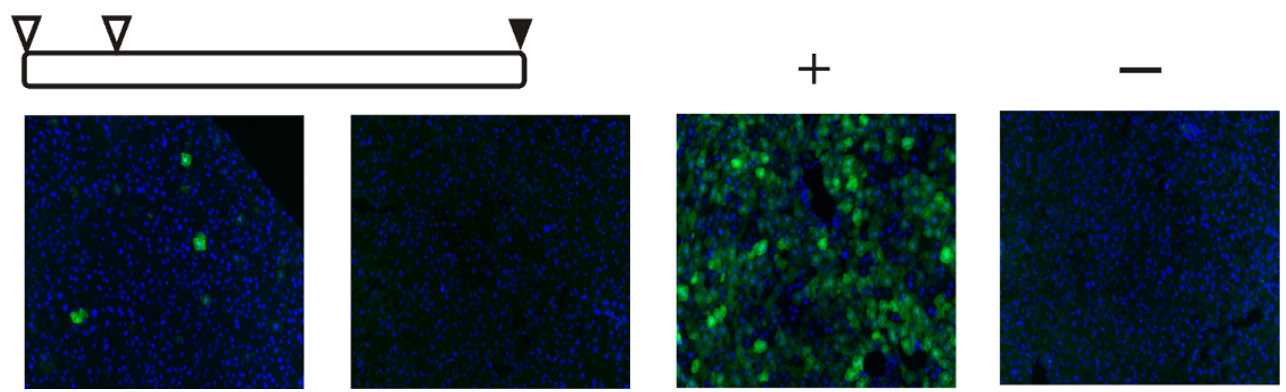

\section{Figure 4}

Reapplication at different developmental stages. EGFP expression two months after AAV-EGFP injection (filled triangles) following AAV expositions (open triangles) at different developmental stages. Animals received intrahepatic AAV-MOCSI injections as indicated on top of the lines and an intrahepatic AAV-EGFP injection 2 months after the last AAV-MOCSI injection. Liver sections of 2 animals are shown for each time point. Positive control animals $(+)$ received only an AAV-EGFP injection. Negative controls (-) received no AAV. Further details are describe in figure I. 


\section{Acknowledgements}

We thank Günter Schwarz (Köln) for providing cPMP and Sebastian Kügler (Göttingen) for rAAVs. This work was supported by the Deutsche Forschungsgemeinschaft (RE 768/I2).

\section{References}

I. Schwarz G, Mendel RR: Molybdenum cofactor biosynthesis and molybdenum enzymes. Annu Rev Plant Biol 2006, 57:623-647.

2. Reiss J: Genetics of molybdenum cofactor deficiency. Hum Genet 2000, 106(2):157-163.

3. Reiss J, Johnson JL: Mutations in the molybdenum cofactor biosynthetic genes MOCSI, MOCS2, and GEPH. Hum Mutat 2003, $21(6): 569-576$.

4. Lee HJ, Adham IM, Schwarz G, Kneussel M, Sass JO, Engel W, Reiss J: Molybdenum cofactor-deficient mice resemble the phenotype of human patients. Hum Mol Genet 2002, I I (26):3309-33I 7.

5. Kugler S, Hahnewald R, Garrido M, Reiss !: Long-term rescue of a lethal inherited disease by adeno-associated virus-mediated gene transfer in a mouse model of molybdenum-cofactor deficiency. Am J Hum Genet 2007, 80(2):29I-297.

6. Garrett RM, Bellissimo DB, Rajagopalan KV: Molecular cloning of human liver sulfite oxidase. Biochim Biophys Acta 1995, I 262(23): $147-149$.

7. Hauck B, Chen L, Xiao W: Generation and Characterisation of Chimeric Recombinant AAV Vectors. Mol Ther 2003, 7(3):419-425.

8. Schwarz G, Santamaria-Araujo JA, Wolf S, Lee HJ, Adham IM, Grone HJ, Schwegler H, Sass JO, Otte T, Hanzelmann P, Mendel RR, Engel W, Reiss J: Rescue of lethal molybdenum cofactor deficiency by a biosynthetic precursor from Escherichia coli. Hum Mol Genet 2004, I3( I 2): 1 249-1255.

9. Snyder RO, Miao C, Meuse L, Tubb J, Donahue BA, Lin HF, Stafford DW, Patel S, Thompson AR, Nichols T, Read MS, Bellinger DA, Brinkhous KM, Kay MA: Correction of hemophilia B in canine and murine models using recombinant adeno-associated viral vectors. Nat Med 1999, 5(I):64-70.

10. Manno CS, Pierce G, Arruda VR, Glader B, Ragni M, Rasko JJ, Ozelo M, Hoots K, Blatt P, Konkle B, Dake M, Kaye R, Razavi M, Zajko A, Zehnder J, Rustagi PK, Nakai H, Chew A, Leonard D, Wright JF, Lessard RR, Sommer JM, Tigges M, Sabatino D, Luk A, Jiang H, Mingozzi F, Couto L, Ertl HC, High KA, Kay MA: Successful transduction of liver in hemophilia by AAV-Factor IX and limitations imposed by the host immune response. nature medicine 2006, I 2(3):342-347.

II. Niemeyer GP, Herzog RW, Mount J, Arruda VR, Tillson DM, Hathcock J, van Ginkel FW, High KA, Lothrop CDJ: Long-term correction of inhibitor-prone hemophilia B dogs treated with liverdirected AAV2-mediated factor IX gene therapy. blood 2009, I 1 3:797-806.

12. Mount JD, Herzog RW, Tillson DM, Goodman SA, Robinson N, McCleland ML, Bellinger D, Nichols TC, Arruda VR, Lothrop CD Jr, High KA: Sustained phenotypic correction of hemophilia B dogs with a factor IX null mutation by liver-directed gene therapy. Blood 2002, 99(8):2670-2676.

13. Nathwani AC, Davidoff AM, Hanawa H, Hu Y, Hoffer FA, Nikanorov A, Slaughter C, Ng CY, Zhou J, Lozier JN, Mandrell TD, Vanin EF, Nienhuis AW: Sustained high-level expression of human factor IX (hFIX) after liver-targeted delivery of recombinant adeno-associated virus encoding the $\mathrm{hFIX}$ gene in rhesus macaques. Blood 2002, 100(5): 1662-1669.

14. Wang L, Calcedo R, Nichols TC, Bellinger DA, Dillow A, Verma IM, Wilson JM: Sustained correction of disease in naive and AAV2pretreated hemophilia B dogs: AAV2/8-mediated, liverdirected gene therapy. Blood 2005, I05(8):3079-3086.

15. Mingozzi F, Maus MV, Hui DJ, Sabatino DE, Murphy SL, Rasko JJE, Ragni M, Manno CS, Sommer JM, Jiang H, Pierce GF, Ertl HC, High $\mathrm{KA}$ : CD8+ T-cell responses to adeno-associated virus capsid in humans. nature medicine 2007, 13(4):419-422.

16. Sabatino DE, Mackenzie TC, Peranteau W, Edmonson S, Campagnoli C, Liu YL, Flake AW, High KA: Persistent expression of $\mathbf{h F} . \mathbf{I X}$ After tolerance induction by in utero or neonatal administration of AAV-I-F.IX in hemophilia B mice. Mol Ther 2007, I 5(9): 1677-|685.

17. Mingozzi F, High KA: Immune responses to AAV in clinical trials. Curr Gene Ther 2007, 7(5):316-324.
18. Ponder KP, Wang B, Wang P, Ma X, Herati R, Wang B, Cullen K, O'Donnell P, Ellinwood NM, Traas A, Primeau TM, Haskins ME: Mucopolysaccharidosis I cats mount a cytotoxic T lymphocyte response after neonatal gene therapy that can be blocked with CTLA4-Ig. Mol Ther 2006, I4(I):5-13.

19. Petry H, Brooks A, Orme A, Wang P, Liu P, Xie J, Kretschmer P, Qian $\mathrm{HS}$, Hermiston TW, Harkins RN: Effect of viral dose on neutralizing antibody response and transgene expression after AAVI vector re-administration in mice. Gene Ther 2008, I5(I):54-60.
Publish with Bio Med Central and every scientist can read your work free of charge

"BioMed Central will be the most significant development for disseminating the results of biomedical research in our lifetime. "

Sir Paul Nurse, Cancer Research UK

Your research papers will be:

- available free of charge to the entire biomedical community

- peer reviewed and published immediately upon acceptance

- cited in PubMed and archived on PubMed Central

- yours - you keep the copyright
BiolMedcentral 